УДК $621.382 .2 / 3$

\title{
ТЕХНОЛОГИЧЕСКИЕ ОСОБЕННОСТИ ИЗГОТОВЛЕНИЯ СВЧ ПРИБОРА С БАРЬЕРАМИ ШОТТКИ
}

\author{
В. С. ДМИТРИЕВ, Л. Б. ДМИТРИЕВА, Е. Я. ШВЕЦ \\ Запорожская государственная инженерная академия, \\ Украина, Запорожье, 69006, пр-т Соборный, 226
}

\begin{abstract}
Аннотация. В настоящее время исследования и разработка гетеропереходов ведутся в направлениях поиска новых композиций и технологических режимов создания омических и барьерных переходов к арсениду галлия. Переход к металлизации на основе серебра, имеющего большие по сравнению с золотом тепло- и электропроводность и относительно небольшой коэффициент диффузии в арсенид галлия, должен повысить технические характеристики изделий. Одной из важнейших технологических операций при формировании омических контактов и барьеров Шоттки является термический отжиг. Контакты на основе серебра к арсениду галлия изготовлены в вакууме методом термического испарения. Разработаны режимы нанесения и термической обработки при создании омических контактов $\mathrm{Ag}-\mathrm{Ge}-\mathrm{In} / n-n^{+} \mathrm{GaAs}$ с удельным контактным сопротивлением $\rho_{\mathrm{K}}=(5 \ldots 7) \times 10^{-5}$ Ом.см ${ }^{2}$. Установлено влияние температуры подложки при напылении серебра, температуры отжига на высоту барьера Шоттки $\mathrm{Ag} / n-n^{+} \mathrm{GaAs}$, коэффициент инжекции $\gamma$ и фактор неидеальности $\eta$.
\end{abstract}

Ключевые слова: барьер Шоттки; СВЧ прибор; арсенид галлия; эпитаксиальная пленка; травление; режим термообработки; контакт

\section{ВВЕДЕНИЕ}

Развитие средств мобильной связи и планшетных устройств, использование высокоскоростных беспроводных телекоммуникационных средств, увеличение пропускной способности волоконно-оптических систем, требующих увеличения скорости передачи данных, приводит к необходимости резкого увеличения доли электронных приборов СВЧ диапазона [1-6], которые изготавливаются на основе электронного арсенида галлия.

В настоящее время исследования и разработки гетеропереходов ведутся в направлениях поиска новых композиций металл-арсенид галлия [7-9], разработки технологических режимов [8-10], которые могут обеспечить вос- производимость параметров СВЧ приборов с барьерами Шоттки (БШ).

Несмотря на то, что основные физические процессы в гетеропереходах металл-арсенид галлия достаточно хорошо изучены [10-12], до сих пор существуют разногласия в вопросах установления причин отклонения вольтамперных характеристик от идеальных [13-16], что связано с технологическими особенностями их изготовления.

В настоящее время наиболее отработаны технологии изготовления гетеропереходов металл-арсенид галлия на основе золота [13-16]. Однако, переход к металлизации на основе серебра, имеющего большую по сравнению с золотом тепло- и электропроводность и относительно небольшой коэффициент диффузии в 


\section{БИБЛИОГРАФИЧЕСКИЙ СПИСОК}

1. Белоус, А.И.; Солодуха, В.А.; Шведов, С.В. Космическая электроника: в 2 кн. Кн. 2. М.: Техносфеpa, 2015. 489 c.

2. Швец, Е.Я.; Коломоец, А.Г.Оценка перспектив применения арсенида галлия и сплавов на его основе в качестве материалов для солнечных элементов. Металургія, № 30, С. 132-136, 2013. URI: http://www. zgia.zp.ua/gazeta/Metallurgy 30_132.pdf.

3. Загирняк, М.В.; Оксанич. А.П.; Петренко, В.Р.; Притчин, С.Э.; Тербан, В. А. Создание современных технологий выращивания структурно-совершенных слитков электронного арсенида галлия. Сборник научных трудов 5-й Международной научной конференции «Функциональная база наноэлектроники». Кацивели: ХНУРЭ, 2012, С. 5-13. 
4. Зуев, С.А.; Килесса, Г.В.; Асанов, Э.Э.; Старостенко, В.В.; Покрова, С.В.Зависимость проводимости от толщины активной области в тонкопленочных диодах Шоттки на GaAs. Физика и техника полупроводников, Т. 50, № 6, С. 825-829, 2016. URI: http:// journals.ioffe.ru/articles/43212.

5. Park, Chan Hyeong; Lee, Jong-Ho. Formulas of 1/f noise in Schottky barrier diodes under reverse bias. Solid-State Electronics, Vol. 69, P. 85-88, 2012. DOI: 10.1016/j.sse.2011.11.030.

6. Платонов, С.В.; Пермяков, Н.В.; Селезнев, Б. И.; Мошников, В.А.; Козловский, Э.Ю.; Осипов, А.М. Малошумящие арсенид-галлиевые усилители при воздействии электромагнитных помех повышенных интенсивностей. Вестник Новгородского государственного университета, № 67, С. 29-32, 2012. URI: http:// www.novsu.ru/file/1010219.

7. Ерофеев, Е.В. Формирование контактов металл-полупроводник с металлизацией на основе $\mathrm{Al}$ и $\mathrm{Cu}$ для GaAs CBЧ транзисторов с высокой подвижностью электронов : автореф. дис. на соискание ученой степени канд. техн. наук : спец. 01.04 .04 «физическая электроника». Томск, 2012, 24 с. URI: http://old.tusur. ru/export/sites/ru.tusur.new/ru/science/education/diss/20 12/03/01.pdf

8. Кольцов, Г.И.; Диденко, С.И.; Черных, А.В.; Черных, С. В.; Чубенко, А.П.; Свешников, Ю.Н.Контакты Шоттки к высокоомным эпитаксиальным слоям GaAs для детекторов частиц и квантов. Физика и техника полупроводников, № 8, C. 1088-1093, 2012. URI: http://journals.ioffe.ru/articles/7776.

9. Tecimer, H.; Türüt, A.; Uslu, H.; Altındal, Ş.; Uslu, İ. Temperature dependent current-transport mechanism in $\mathrm{Au} /(\mathrm{Zn}$-doped)PVA/n-GaAs Schottky barrier diodes (SBDs). Sensors and Actuators A: Physical, Vol. 199, P. 194-201, 2013. DOI: 10.1016/j.sna.2013. $\underline{05.027}$.

10. Jayavel, P.; Kumar, J.; Ramasamy, P.; Premanand, R. On the evaluation of Schottky barrier diode parameters of $\mathrm{Pd}, \mathrm{Au}$ and $\mathrm{Ag} / \mathrm{n}-\mathrm{GaAs}$. Indian J. Eng. Materials Sci., Vol. 7, No. 5-6, P. 340-343, 2000. URI: http://nopr.niscair.res.in/handle/123456789/24425.

11. Дмитриев, В.С.; Швец, Е. Я. Технологические особенности изготовления усилителя бегущей волны. Сборник материалов 10-й международной молодежной научно-технической конференции «Современные проблемы радиотехники и телекоммуникаций «PT-2014». Севастополь: СевНТУ, 2014. С. 158. ISBN 978-617-612-072.

12. Huo, P.; Rey-Stolle, I. Ti/Pd/Ag contacts to n-type GaAs for high current density devices. J. Electronic Materials, Vol. 45, No. 6, P. 2769-2775, 2016. DOI: 10.1007/s11664-016-4432-6.

13. Özavc1, E.; Demirezen, S.; Aydemir, U.; Altındal, Ş. A detailed study on current-voltage characteristics of $\mathrm{Au} / \mathrm{n}-\mathrm{GaAs}$ in wide temperature range. Sensors and Actuators A: Physical, Vol. 194, P. 259-268, 2013. DOI: $10.1016 /$ j.sna.2013.02.018.
14. Hudait, M. K.; Venkateswarlu, P.; Krupanidhi, S. B. Electrical transport characteristics of $\mathrm{Au} / \mathrm{n}-\mathrm{GaAs}$ Schottky diodes on n-Ge at low temperatures. Solid-State Electronics, Vol. 45, No. 1, P. 133-141, 2001. DOI: $\frac{10.1016 / \mathrm{S} 0038-1101(00) 00230-6 .}{15 .}$

15. D. Korucu; Turut, A.; Altındal, Ş. The origin of negative capacitance in $\mathrm{Au} / \mathrm{n}-\mathrm{GaAs}$ Schottky barrier diodes (SBDs) prepared by photolithography technique in the wide frequency range. Current Appl. Phys., Vol. 13, No. 6, P. 1101-1108, 2013. DOI: 10.1016/j.cap.2013.03.001.

16. Leroy, W. P.; Opsomer, K.; Forment, S.; Van Meirhaeghe, R. L. The barrier height inhomogeneity in identically prepared $\mathrm{Au} / \mathrm{n}-\mathrm{GaAs}$ Schottky barrier diodes. Solid-State Electronics, Vol. 49, No. 6, P. 878-883, 2005. DOI: $10.1016 /$ j.sse.2005.03.005.

17. Lv, Jing; Lai, Fachun; Lin, Limei; Lin, Yongzhong; Huang, Zhigao; Chen, Rong. Thermal stability of $\mathrm{Ag}$ films in air prepared by thermal evaporation. Appl. Surface Sci., Vol. 253, No. 17, P. 7036-7040, 2007. DOI: $\underline{10.1016 / j . a p s u s c .2007 .02 .058 .}$.

18. Kim, H. C.; Alford, T. L. Improvement of the thermal stability of silver metallization. J. Appl. Phys., Vol. 94, No. 8, P. 5393-5395, 2003. DOI: $\underline{10.1063 / 1.16}$ $\underline{09646}$

19. Sugawara, K.; Kawamura, M.; Abe, Y.; Sasaki, $\mathrm{K}$. Comparison of the agglomeration behavior of $\mathrm{Ag}(\mathrm{Al})$ films and $\mathrm{Ag}(\mathrm{Au})$ films. Microelectron. Eng., Vol. 84, No. 11, P. 2476-2480, 2007. DOI: 10.1016/j.mee.2007.05. 050 .

20. Kawamura, M.; Yamaguchi, M.; Abe, Y.; Sasaki, $\mathrm{K}$. Electrical and morphological change of Ag-Ni films by annealing in vacuum. Microelectron. Eng., Vol. 82, No. 3-4, P. 277-282, 2005. DOI: 10.1016/j.mee.2005.07.035.

21. Christou, A. Solid phase formation in $\mathrm{Au}: \mathrm{Ge} / \mathrm{Ni}$, $\mathrm{Ag} / \mathrm{In} / \mathrm{Ge}$, In/Au: Ge GaAs ohmic contact systems. Solid-State Electronics, Vol. 22, No. 2, P. 141-149, 1979. DOI: 10.1016/0038-1101(79)90106-0.

22. Дмитрієв, В. С.; Швець, Є. Я.; Дмитрієва, Л.Б. Технологічні особливості виготовлення омічного контакту до GaAs. Науковий вісник КУЕІТУ «Нові технологї̈». № 1-2, С. 48-50, 2013.

23. Мурель, А.В.; Данильцев, В.М.; Демидов, Е. В.; Дроздов, М.Н.; Шашкин, В.И. Влияние быстрого термического отжига на параметры арсенидгаллиевого низкобарьерного диода с приповерхностным delta-легированием. Физика и техника полупроводников, T. 47, № 11, C. 1481-1485, 2013. URI: http://journals. ioffe.ru/articles/5121.

24. Kampen, T. U.; Park, S.; Zahn, D. R. T. Barrier height engineering of $\mathrm{Ag} / \mathrm{GaAs}(100)$ Schottky contacts by a thin organic interlayer. Appl. Surface Sci., Vol. 190, No. 1-4, P. 461-466, 2002. DOI: 10.1016/S0169-4332(01)00 919-9.

25. Нисков, В.Я. Измерение переходного сопротивления омических контактов к тонким слоям полупроводников. Приборы и техника эксперимента, № 1, С. 235-237, 1971. 
26. Нисков, В.Я.; Заддэ, В.В.; Зайцева, А.К.; Стрельцова, В.И. Измерение переходного сопротивления омических контактов к тонким слоям полупроводников. Приборы и техника эксперимента, № 2, С. 240-242, 1971.

27. Нисков, В. Я.; Кубецкий, Г. А. Сопротивление омических контактов к тонким слоям полупроводни- ков. Физика и техника полупроводников, Т. 4, № 9, С. 1806-1808, 1970.

28. Sze, S. M.; Kwok, K. N. Physics of Semiconductor Devices, 3rd ed. Hoboken: A John Wiley \& Sons, Inc., 2006. $832 \mathrm{p}$ 